


\section{Article Artículo Paper Experiència de la 2 participació de les persones privades de llibertat en el procés de millora en competències ciutadanes}

\section{Jordi Enjuanes i Llop ${ }^{1}$}

\section{Resum}

Xavier Escribano

Segura $^{2}$
La finalitat dels sistemes penals és fomentar processos de participació i educació ciutadana dins els Centres Penitenciaris, per retornar a la societat ciutadans compromesos amb la comunitat i la millora de la cohesió social, evitant així la reiteració del fet delictiu i millorant el procés d'inclusió social. En aquest sentit, la participació és un mitjà ideal per formar als ciutadans en valors democràtics $i$, per tant, un dels mitjans més potents per a fomentar la pau i la convivència social. El present article introdueix una nova manera d'entendre l'execució penal, on l'educació ciutadana i la conformació de ciutadans participatius, crítics i compromesos amb la comunitat supera la clàssica finalitat retributiva. La implementació del Model de Participació i Convivència a les presons catalanes, concretament al Centre Penitenciari Lledoners, on mostra

1. Educador i Treballador social. Estudiant de doctorat en educació. Investigador del grup de recerca GIAS de la Facultat d'Educació Social i Treball Social Pere Tarrés - Universitat Ramon Llull. Educador Social al Departament de Justícia de la Generalitat de Catalunya.

2. Sociòleg. Estudiant de doctorat en educació. Investigador del grup de recerca GIAS de la Facultat d'Educació Social i Treball Social Pere Tarrés - Universitat Ramon Llull. 
beneficis significatius tant en la millora de la qualitat de vida, com en el procés de retorn a la comunitat. El procés de canvi identitari a través de l'acció i l'acompanyament educatiu, permet i facilita el procés de reinserció social.

En aquest article repassarem els beneficis dels espais de participació en el procés de canvi i reeducació i la millora de la qualitat de vida dels interns. Es farà a través de les veus dels professionals que hi conviuen, tant d'interior com de tractament, i que formen part del Centre Penitenciari.

Paraules clau: Reinserció social, centres penitenciaris, Participació, acció comunitària, ciutadania. 


\section{Introducció}

La transgressió de la convivència que representa la realització d'un delicte suposa una inestabilitat en l'ordre social que cal ser reconduït per l'Estat, que mostra la seva capacitat sancionadora envers al fet delictiu. Un ius puniendi estatal que ha tingut diferents intensitats en funció de la voluntat o mirada sancionadora. Des de models altament retributius (Jackobs, 2003) a models clarament educatius i integradors (Enjuanes et alt, 2016; Morata, 2014). És durant la modernitat tardana on la retribució i la gestió del risc han estat una constant en les polítiques penals (Fernandez, 2013; Garland, 2005). Tanmateix, al mateix moment s'han assajat models penals exitosos que miren d'apropar-se al manament constitucional de la reeducació i la reinserció social, evidenciant un procés pendular en quant a l'anàlisi de la finalitat de la pena (Cervello, 2005). Si es vol satisfer l'objectiu últim del sistema penitenciari, cal fomentar models penitenciaris educatius que millorin i impulsin accions de canvi positiu en les persones privades de llibertat. La càrrega humanista que aquests duen implícita, així com el compromís adquirit els equips de professionals socials en l'acompanyament i retorn a la comunitat de les persones excloses (Caride \& Gradaí1le, 2013; Enjuanes \& Vinyals, 2016; Rodríguez, García, Álvarez, Longoria, \& Noriega, 2013), els fan especialment pertinent per aquest propòsit.

Prenent com a base el manament legal ${ }^{3}$, entenem que el sistema penitenciari té com a principal funció orientar les seves accions, en primer lloc, cap a processos de desistiment (Laub i Sampson, 2001; Maruna, 2001), canvi identitari (McNeill, 2016) i millora competencial (funció reeducativa). I en segon lloc, pretén assegurar la capacitat de la persona a viure en comunitat, respectant les normes i participant de forma activa en el desenvolupament i millora de la cohesió social del territori o comunitat on viu (funció reinsertadora) (Del Pozo i Añaños, 2013; Gil, 2010). Per tant, la institució penitenciària és concebuda no com una institució de càstig i únicament retributiva del mal fet, sinó com una institució fonamentalment educativa que potencia accions intencionades de millora de les competències socials, possibilitant l'assumpció de valors prosocials. Una institució que és part i forma part d'una comunitat, fomentant la participació tant de la població civil dins el Centre Penitenciari, com possibilitant que el propi Centre Penitenciari sigui part activa

3. L'article primer de la Llei Orgànica 1/79 General Penitenciària diu textualment "Les institucions penitenciàries regulades en la present Llei tenen com a finalitat primordial la reeducació i la reinserció social dels sentenciats a penes i mesures penals privatives de llibertat". 
en la comunitat (Enjuanes et alt, 2014; Rodriguez et alt, 2013). En aquest aspecte, els equips de professionals, i especialment aquells que formem part de l'àmbit social, tenim un important compromís en el desenvolupament de models penals humans, justos i efectius (Cervelló, 2005).

L'any 1984 es va transferir a la Generalitat de Catalunya les competències en matèria penitenciària, que, si bé no contempla el traspàs de la seva capacitat legislativa, si permet una plena gestió en l'execució de les penes en el territori català (Tamarit, 2016). Al llarg d'aquest temps, Catalunya ha apostat per un model penitenciari que fomenti el desistiment delictiu i al mateix temps asseguri processos d'acompanyament educatiu i de retorn a la comunitat efectius (Generalitat de Catalunya, 2011). En el darrer estudi de reincidència (Capdevila, 2014) es mostren dades que fan visibles l'èxit d'aquest model en la prevenció de la reincidència delictiva. Les dades mostren una reincidència del 30’2\%, del que es desprèn que set de cada deu persones que surten dels centres penitenciaris catalans no tornen a ingressar. Tot i que la quantitat de variables que entren en joc no permeten precisar una sola causa per aquest fenomen (Capdevila, 2014), si que és cert que el canvi cap a models educatius en el sistema d'execució de penes a Catalunya ajuda sensiblement a consolidar aquesta tendència. Un dels canvis més significatius en la darrera dècada ha estat el foment i l'impuls de la participació de tots els agents implicats dins i fora dels Centres Penitenciaris catalans. La participació, doncs, és un element d'èxit en la millora de la qualitat de vida (Rogriguez et alt, 2018) i en el procés de retorn a la comunitat. Els Centres Penitenciaris han de ser espais educatius on, a través del treball experiencial i la pràctica participativa, possibilitin l'aprenentatge de noves competències i valors socials (Enjuanes, Escribano i Sanchez, 2016).

Tanmateix, la influència dels processos participatius en la reinserció social i la millora de la qualitat de vida de la població interna a Catalunya és un àmbit de recerca força recent, pel que les publicacions en aquests sentit no són encara gaire nombroses. L'article pretén exemplificar com la creació d'espais participatius amb les persones privades de llibertat, milloren la construcció de valors socials compartits, augmenten la qualitat de vida, i permeten una millorar de les competències socials, elements tots ells que milloren el procés de motivació al canvi. Des d'aquest text pretenem aportar informació significativa en aquesta matèria que pugui estimular futures recerques i publicacions. 


\section{La participació en el procés de reinserció}

Lèxit d'una institució educativa com els Centres Penitenciaris depèn de una àmplia multidimensionalitat de factors, però l'existència d'una cultura de la participació i d'uns espais possibilitadors es situen com un dels factors claus en l'èxit inclusiu. Les minories afâsiques (Zubero, 2006), els i les sense veu, han trobat tradicionalment el seu espai per fer-se veure i sentir, bé sigui en espais formals, com el context descrit en aquest article, bé sigui a través de revoltes i amotinaments (Lorenzo, 2013). La democràcia, necessita, per un costat, d'una cultura participativa present en la institució com a part activa del seu propi canvi i, de l'altra, requereix pràctica (Zubero, 2006), espais d'aprenentatge vivencial en el diàleg i el creixement. Una pràctica que permeti posar en agenda els problemes socials, percebuts pel usuaris i que generen malestar. Uns problemes socials que han de passar a la pròpia agenda institucional, convertint-se, doncs, en un problema públic (Zubero, 2014) responsabilitat de totes i tots els que en formen part.

Però participar no és generar problemes als altres, no és només fer visible el malestar i demanar reparacions. L'afasia dels col-lectius exclosos com la població interna (Marcuello-Servós \& García-Martínez, 2011; Valverde, 2014), no es soluciona tant sols donant veu i una plataforma per fer-la sentir (Zubero, 2014). Participar és construir amb i des de la comunitat la resposta a les pròpies necessitats. És en aquest punt que la institució penitenciària ha d'incorporar en la seva cultura espais reals de participació que possibilitin un treball conjunt des de tres dimensions (Barbero i Cortés, 2005):

- Conscientització. Procés en el que hem de fer sentir part activa i promotora del canvi a tots els agents de la comunitat. És tasca dels equips professionals socials, però no exclusiva, el fer sentir partícips del procés de canvis als interns, els familiars, i les entitats socials. Fent palesos els seus malestars i necessitats.

- Mobilització. Aquest despertar, el retorn a l'ús de la veu com a plataforma pel creixement ha de tenir un espai. Aquests espais són les comissions o grups de treball en el que es treballa plegats per la millora del clima social. Espais de treball incorporats en la dinàmica com a espai real i no només des de la formalitat de l'acte, en el que hi participin tots els agents implicats en el procés. 
- Acció. La base del procés de participació. El diàleg i la trobada ha de servir per la transformació. Permet entendre els límits per començar plegats accions comunes de canvi. Una acció que no és responsabilitat d'un sol agent sinó del que tots en són co-responsables i agents de canvi.

El procés de participació, però, requereix de formació. La construcció de ciutadania compromesa (Trilla, 2010) s'assoleix a través de l'educació, de l'aprenentatge social i especialment de l'experiència de la pràctica participativa. Aquells que no han fet sentir la seva veu, han de poder participar del procés. Tanmateix, cal anar en compte, ja que d'afasics en trobem entre la població interna, però també entre els equips de professionals, colllaboradors i familiars que poden no saber i no conèixer els mecanismes de la participació. Per això, el treball participatiu comporta una sèrie de capacitats que cal impulsar (Trilla i Novella, 2011) i que es donen en la pràctica diària de la participació de forma implícita en la seva acció. Es tracta de competències en les que cal anar educant a tots els que en formen part del procés a través de la experiència, però també de la formació reglada:

- Capacitat d'entendre la comunitat com a part del procés de canvi. Cal incorporar els agents comunitaris en el treball interdisciplinari.

- Capacitat comunicativa i de treball en equip, a través de propostes de treball interdisciplinari, situant la població interna en el centre de l'acció i no compartimentant l'estratègia d'intervenció.

- Capacitat creativa i propositiva, cercant noves fórmules, innovadores i creatives que ens permetin assolir els objectius.

- Capacitat de reconèixer-se com a ciutadà actiu i compromès amb la comunitat, fent de la persona part activa en el canvi social. Eliminant el concepte de client i promovent la participació vers el seu propi canvi però també en el de la comunitat.

El centre penitenciari, doncs, és i ha de ser un espai dinàmic i participatiu en el que tots en formin part i se sentin part de la comunitat. Aprendre a participar és aprendre valors ciutadans i, per tant, millorar el posterior procés d'incorporació social. 


\section{El model de participació $i$ convivència}

L'any 2008 s'inicia al Centre Penitenciari Lledoners una nova forma d'entendre la intervenció penitenciària, basada en el foment de la cultura participativa i un treball comunitari de tots els agents implicats en el procés d'incorporació social. El Centre Penitenciari Lledoners, és una presó d'homes que està ubicada a Sant Joan de Vilatorrada (Bages), amb una capacitat per allotjar un màxim de 750 interns. La seva recent creació el fa un centre modern, amb una dotació tecnològica innovadora i una clara aposta al procés de reeducació i reinserció dels interns. És un centre de compliment preeminentment en segon grau de tractament, si bé poden haver interns en regim de tercer grau, primer grau o bé preventius.

El model de Participació i Convivència implementat en el centre, busca la millora del clima social a través del foment i la participació de tots els seus membres (Generalitat de Catalunya, s.d.), possibilitant processos de canvi personal efectiu que permetin iniciar la vinculació i incorporació al medi exterior. Fins el moment, aquests models havien estat exclusius d'unitats o mòduls específics on la voluntat desistora del l'intern n'era un requisit important (Enjuanes et alt, 2014; Rodriguez et alt, 2014; Calan, 2015) evidenciat a través de la signatura d'un compromís conductual. És durant l'any 2013 que aquesta proposta es fa extensiva a tots els mòduls, essent l'únic Centre Penitenciari que proposa una intervenció d'universalitat adaptada per a tota la població, indistintament del grau de motivació al canvi en el que es trobin. Aquesta universalitat adaptada fa referència a l'establiment d'un sistema de participació i cogestió conjunt entre tots els agents: interns, familiars, professionals i entitats socials, adaptats a les necessitats i característiques dels col·lectius. Possibilitant així que l'educació en valors democràtics sigui comú a tots els seus membres, des dels propis interns fins els equips de professionals de l'execució penal, i en sigui un valor per si mateix de la pròpia institució.

L'impacte d'aquest treball aporta dades significatives que reforcen, encara més, els resultats descrits anteriorment. En la recerca objecte d'aquest article s'ha estudiat la reincidència dels interns d'aquest Centre Penitenciari, reproduint la metodologia i anys de seguiment dels casos d'estudis previs com l'estudi de reincidència del Departament de Justícia (Capdevila, 2014). Aquestes dades aporten resultats força satisfactoris, destacant que tant sols el 20\% dels interns retornen al Centre Penitenciari un cop han sortit de lli- 
bertat, dada que no varia si augmenta la complexitat del risc dels interns. Aquests resultats ens indiquen que la implementació de Models de Participació i Convivència suposa no només una millora en la qualitat de vida (Rodriguez et alt,2018) sinó també una millora en les de dades de reincidència. Motivada per les especials característiques d'un model que, a més d'incidir en els factors de risc derivats de la etiologia delictiva, centrant l'acció envers la disminució de la reincidència, possibilita la transmissió de valors i habilitats socials positives que milloren les competències per retornar a la comunitat, incidint en el procés de reinserció. Tot plegat incideix en la construcció d'una ciutadania responsable i compromesa i millora els processos d'incorporació social, alhora que es fomenta un canvi identitari que permeti la consolidació dels processos de desistiment delictiu (Laub i Sampson, 2001; Maruna, 2001).

El model de participació i convivència s'assenta sobre quatre eixos principals:

- Procés d'acollida, acompanyament educatiu i millora de la qualitat de vida subjectiva. A través de la implicació dels equips de professionals i dels interns, amb un rol destacat del Promotor Cívic, amb el que es pretén millorar el procés d'entrada a un Centre Penitenciari. És evident que el suport social percebut serà una causa base en el procés de desistiment (Bustamante et alt, 2016) així com la millora de la qualitat de vida subjectiva augmenta la implicació de l'intern en la pròpia institució (Rodriguez et alt, 2018).

- Millora de les competències personals i socials. La intervenció en la etiologia delictiva permetrà a la persona identificar situacions i factors de risc, tot evitant $\mathrm{o}$ gestionant de forma adequada aquestes situacions. Una intervenció basada en el model de Good Lives (Gil, 2013) farà que la intervenció, a més d'incidir en els factors propis de la etiologia delictiva, permeti el desenvolupament de la seva pròpia voluntat en el procés de canvi. El desistiment delictiu passa per acompanyar a la persona (Alonso i Funes, 2009) en el seu propi procés de canvi vers la construcció d'una nova identitat (Laub i Sampson, 2001).

- Foment dels vincles comunitaris. A través de la participació de la comunitat, l'intern manté vincles amb les entitats externes que l'acompanyaran en el procés de transició a la llibertat. A Catalunya, les entitats organitzades a través de la Taula de Partici- 
pació Social (Generalitat de Catalunya, s.d.b), participen de la gestió del centre i possibiliten un treball de continuïtat un cop l'intern comença a sortir de llibertat.

Junt a les entitats, els familiars ocupen un lloc important en el treball de vinculació i suport en comunitat. El professional del treball social, nexe central en aquest procés, és el responsable de possibilitar el seguiment, retrobament i formació a les famílies per entendre el fet delictiu i conèixer el seu paper un cop l'intern surt en llibertat (Marti i Cid, 2015).

- Millora de la participació i construcció de ciutadania activa. El darrer punt, i no menys important, centra la intervenció en aprendre, a través de l'experiència vivencial, les pràctiques participatives que possibilitin la consolidació d'una ciutadania compromesa amb la seva comunitat. El coneixement de la norma i els límits, el respecte cap a l'altre, la construcció cultural, el retorn actiu a la comunitat i la gestió del conflicte són alguns dels aspectes singulars en aquest eix (Hirschi, 2003; Prat \& Cullen, 2000), que han de permetre que els interns, dins i fora del propi centre penitenciari, es sentin part activa de la comunitat i reclamin el seu propi espai. La ciutadania compromesa s'assoleix a través de l'educació (Trilla, 2010), i és a través de l'educació que el centre ha de possibilitar espais de conscientització, mobilització i acció participativa que permetin aquest aprenentatge (Barbero i Cortés, 2005).

És precisament en aquest darrer eix que ens centrarem en el nostre article. Incidirem en com l'educació en participació millora la construcció de comunitat dins el Centre Penitenciari, alhora que possibilita l'adquisició de competències socials que incideixen en el procés d'incorporació social.

\section{Metodologia}

L'objectiu de la recerca és l'estudi de la significació del concepte de participació dins el context penitenciari, així com l'efecte que produeix tant en la institució com en el propi procés de reinserció. Per aquest motiu, i davant la necessitat de respondre al com i el per què es duen a terme certes pràctiques en experiències concretes com les que es descriuen a aquest article, i donada l'especial idiosincràsia dels centres penitenciaris, s'ha optat per l'estudi de cas com a enfocament metodològic (Yin, 1984; Diaz et alt, 2011). 
En relació a l'anàlisi i interpretació de les dades, s'ha dut a terme un disseny mixt on les dades qualitatives han tingut una especial rellevància. L'anàlisi de les dades quantitatives és d'abast descriptiu i cerca visualitzar de forma sintètica l'opinió de les persones enquestades respecte a diversos elements de la qualitat de vida i els processos participatius dins el Centre Penitenciari. Per fer-ho, han participat un total de 251 interns del Centre Penitenciari, d'una mostra total de 850 persones. S'ha emprat el qüestionari Measuring Quality of Prison Live - MQPL (Liebling et alt, 2011) amb un total de 128 preguntes en relació a 5 dimensions. Els qüestionaris s'han administrat al llarg de tres jornades seguides, i els interns han tingut un dia sencer per tal de poder-lo respondre, recollint-lo els equips d'educadors socials i entregant als equips de recerca.

Pel que respecta a l'estudi qualitatiu, s'han dut a terme un seguit d'entrevistes semi-estructurades a informants clau. Per fer-les s'ha contactat amb la direcció del Centre qui ha proposat les dates més adequades per fer-les. Les entrevistes han tingut una durada de 45 minuts cadascuna i han participat un total de 15 persones: 6 interns i 9 professionals, tant d'interior com de tractament. El guió de les entrevistes ha constat de quatre apartats coincidint amb els blocs objecte de l'estudi d'investigació que emmarca el present article: Millora de la qualitat de vida i del procés d'acollida, foment dels processos d'aprenentatge en relació a la etiologia delictiva, foment dels vincles socials i comunitaris, i, millora dels processos de participació. En aquest article, només s’inclouen el resultats pertanyents als darrer bloc degut a la seva rellevància respecte al tema principal d'aquest. Un cop realitzades les entrevistes, s'han transcrit i codificat mitjançant la lectura iterativa de les dades i la codificació axial de les mateixes.

En tot el procés de recerca s'han respectat els criteris ètics en la investigació. Els agents entrevistes han participat de forma voluntària en la investigació, així com les dades personals de les persones participants s'han conservat anònimes per respectar la seva intimitat. Aquest fet ha permès garantir que es poguessin expressar amb llibertat i sense por a cap mena de coacció. Els resultats que es presenten a continuació és un buidatge parcial de tota la informació derivada de la investigació i que ens aporta resultats entorn la importància dels processos participatius en la millora de la qualitat de vida i el procés de reinserció. 


\section{Resultats}

Els resultats han estat analitzats a partir de l'estudi de la dinàmica del Centre Penitenciari Lledoners. En concret, a través de les entrevistes i qüestionaris de qualitat de vida, s'han analitzat tant els espais de participació que tenen els interns (consell de mòdul i espais participatius) com els espais de l'activitat de vida diària (organització del centre, temps de lleure, relació amb els equips de professionals) que permetin poder mesurar els aspectes a analitzar. Per fer-ho, l'equip d'investigació ha participat com a observador en una jornada de la vida diària dels interns, fet que ha permès identificar de forma clara els espais i dinàmiques inherents en el centre penitenciari que permetin fomentar els espais participatius. En concret hem estat presents en la realització d'un programa de tractament, en les comissions de mòdul, en una reunió de seguiment del procés d'acollida amb els Promotors Cívics, i els espais d'organització general com és la vida diària en un pati del Centre Penitenciari.

En aquest punt mostrarem els resultats extrets tant de les entrevistes qualitatives realitzades als participants com dels resultats del qüestionari MQPL que acompanyen i reforcen les afirmacions realitzades per aquests. Hem dividit les aportacions de les persones participants en tres blocs, que ajudaran a sistematitzar i ordenar la informació rebuda:

- Millora de la qualitat de vida i procés de reinserció.

- Canvi en la cultura penitenciària.

- Funcionament i organització dels sistemes de participació.

\section{a. Millora de la qualitat de vida i del procés de reinserció}

Un dels aspectes més ben valorats pels interns, és el nivell de qualitat de vida percebut. Els interns del Centre Penitenciari la valoren de forma satisfactòria, situant aquesta en 3 punts sobre un màxim de 5. Si bé és més baixa que en unitats en la que existeix motivació al canvi i un procés selectiu d'entrada, estudis recents aporten dades que demostren que és significativament superior que el d'altres Centres Penitenciaris catalans que no apliquen el model (Rodriguez, Larrauri i Güerri, 2018). 
Aquesta bona valoració de la qualitat de vida es deu especialment al treball educatiu que es fa dins el Centre Penitenciari. Aquest s'emmarca en un model de participació que suposa un espai d'aprenentatge i supera antics models retributius i de càstig, i en el que la millora de les competències personals i socials són un element clau en el procés de sortida en llibertat. Els interns perceben el Centre Penitenciari com un espai i un temps d'oportunitat pel canvi, que fomenta la construcció de ciutadans compromesos en el seu propi procés i, alhora, en la millora de la pròpia comunitat. Així ho indica les respostes obtingudes del Qüestionari MQPL.

\section{Gràfic 1. Mitjana de respostes dels interns en el qüestionari MQPL en relació al} treball educatiu dins el centre.

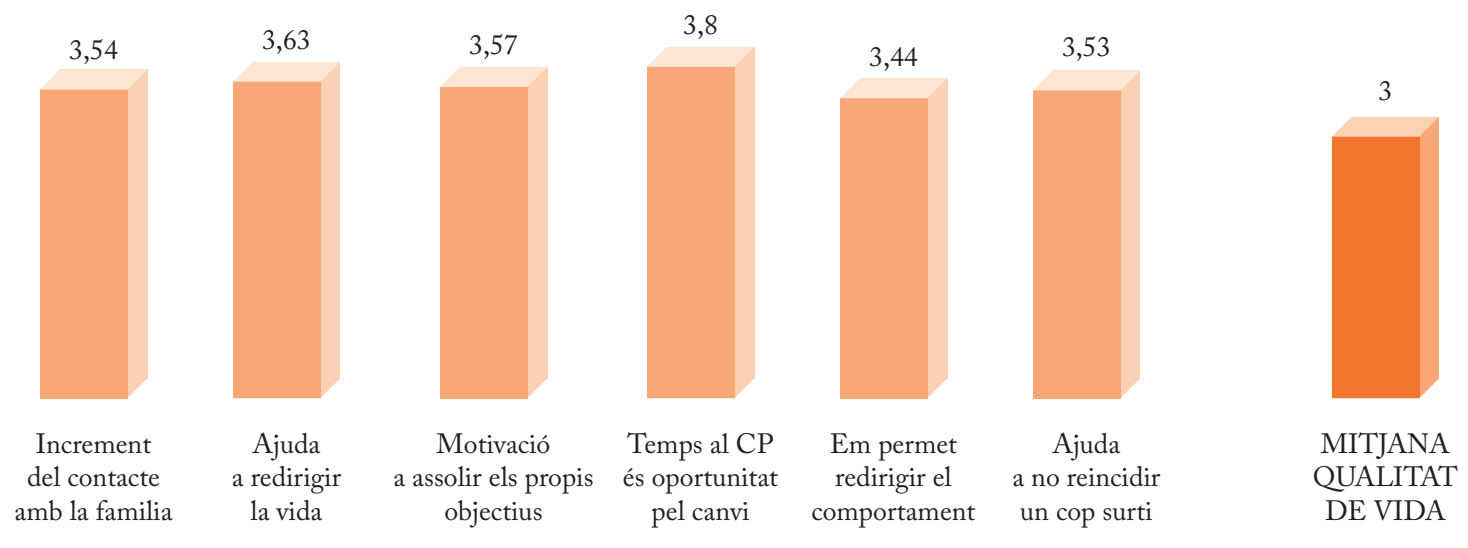

En el gràfic 1 es percep la importància de la percepció del Centre Penitenciari com un espai d'oportunitat al canvi. Els nous centres han de ser espais amables que acompanyin a l'intern en la pròpia identificació dels factors de risc. Aquest procés requereix d'entorns agradables i de l'acompanyament dels professionals a través d'espais on l'intern recuperi la veu i es senti identificat.

De la mateixa manera ho confirmen els entrevistats quan són preguntats per la finalitat del centre penitenciari. Tots els agents entrevistats, equip directiu, professionals i interns, coincideixen en identificar entre les finalitats bàsiques del sistema penitenciari: el treball i acompanyament en el procés de canvi de la persona per assegurar processos d'incorporació efectius. Acompanyament que va precedit d'un treball educatiu vivencial mitjançant la participació activa dins el propi centre. Es destaca la importància que els equips de professionals del centre entenguin aquesta funció, tal i com es descriuen en les entrevistes: 
"Que no torni perquè hagi incorporat les suficients competències com per que pugui tenir una vida respectable" Director

"Promocionar aquest model repercuteix positivament en el seu procés de reinserció. Aprenen d'alguna manera a relacionar-se de determinades formes $i$ després poden traslladar-ho fora (...) Aquests espais són molt valuosos i cal que es cuidin encara més" Treballadora social

"És aquesta corresponsabilització de totes les coses, el que dóna contingut a la persona i sentit. Si d'alguna manera aprens a responsabilitzar-te, t'ho emportes quan surtis del centre" Educadora social

Juntament amb aquest bon treball en el procés de canvi, també es destaca de forma significativa la evidència del tracte que els interns reben de la institució en general i dels professionals en particular. Un espai preeminentment educatiu és un espai de relació horitzontal on desapareixen les arbitrarietats i els abusos de poder, propis d'institucions penitenciària arcaiques.

No obstant, els interns, del que es desprèn del qüestionari, perceben certa mancança i necessitat de millora en el procés d'acompanyament individual. Actualment, encara existeixen traces d'individualisme que cal anar consolidant per tal d'incorporar a la nova comunitat els interns que entren de nou en un centre Penitenciari.

\section{Gràfic 2. Mitjana de respostes del qüestionari MQPL en relació a la Qualitat de vida.}

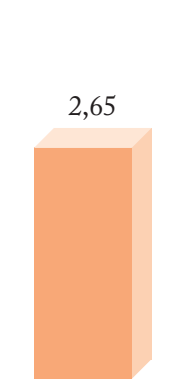

Em vaig sentir cuidat els primers dies
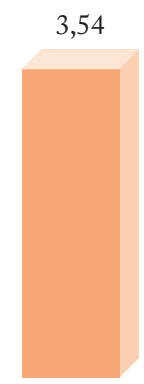

E1 tracte dels professionals és humanitari

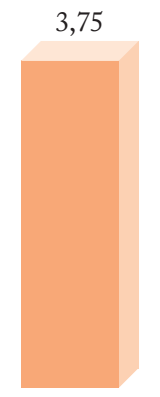

Els professionals em tracten amb amabilitat

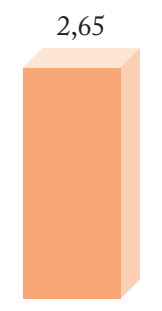

Em vaig sentir sol els primers dies

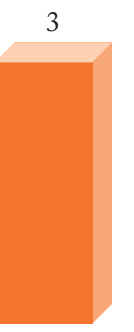

MITJANA

QUALITAT

DE VIDA 
És significatiu la bona valoració dels interns del tracte rebut per part dels equips de professionals del centre en el procés d'internament, front la valoració al llarg del procés d'acollida i acompanyament els primers dies d'internament, inferiors aquestes a la mitjana. En aquest sentit, les persones entrevistades, especialment interns però també els equips directius, insisteixen en la importància del paper dels equips de professionals penitenciaris en el canvi del propi intern, fet que denota la importància de reforçar aquest paper. E1 canvi identitari s'assoleix des de la relació entre els professionals i l'intern.

"Han d'oferir quelcom nou, canviar el ritme de la presó (...) si us plau que treguin el talego del mig, si volen que canviem no podem seguir fent el mateix." Intern

"Aquests espais de participació, els escenaris comunitaris tenen molt valor, no només perquè incideixen directament en la rehabilitació, sinó perquè fa que les competències dels professionals siguin majors" Director

La participació, com es desprén del que diuen les persones entrevistades, permet millorar el procés de canvi identitari. La recerca del jo, del nou jo, que ha de suposar l'inici del procés de reeducació i posterior reinserció, passa per entendre's el propi intern com un subjecte en procés de canvi i amb la capacitat d'assumir valors prosocials, fins ara no present en el seu procés de vida. La participació i els espais participatius, permeten, a més d'experimentar en el necessari treball en equip i relació amb el grup d'iguals, entendre's un mateix com a subjecte de canvi, apoderant-lo en aquest procés.

\subsection{Canvi en la cultura penitenciaria}

Un dels aspectes principals en la implementació del model de Participació i Convivència plantejat, és el canvi en la cultura del propi sistema penitenciari. Es deixen de banda els models retributius per apropar-se a models de tipus sòcio-educatiu, on el rol dels equips de professionals, especialment de l'àmbit social, és un element central (tot i que no l'únic) en el procés de canvi de les persones internes. Un rol que ha de fomentar l'aprenentatge de competències i valors socials que millorin la vida en comunitat i facilitin el procés de desistiment de l'intern, a través d'accions programades i de les activitats de la vida diària. L'intern passa a ser, doncs, un subjecte actiu en aquest procés. El model pro- 
posat vol superar els models clínics i presenta la persona privada de llibertat com a agent actiu en el seu procés de canvi. És corresponsable en la consecució dels objectius plantejats.

Aquest treball és possible gràcies als espais participatius i deliberatius, on a través de l'acció conjunta entre professionals, interns i col-laboradors s'inicien processos de desenvolupament comunitari, amb la construcció compartida de valors socials així com la definició d'estratègies conjuntes als problemes que presenta el dia a dia. Aquests espais de diàleg permeten l'assoliment d'altres formes de relació, i el reconeixement dels agents de la comunitat com a ésser visibles i necessaris pel bon desenvolupament, millorant significativament la convivència i la relació entre els mateixos. Així es mostra en les respostes aportades per les persones internes en el Centre, i assenyalades en el gràfic 3, identificant la bona relació amb els equips de professionals, entenent aquest vincle com un element clau en el procés de canvi

\section{Gràfic 3. Mitjana de respostes del qüestionari MQPL en relació a la millora de la convivència en el Centre Penitenciari.}

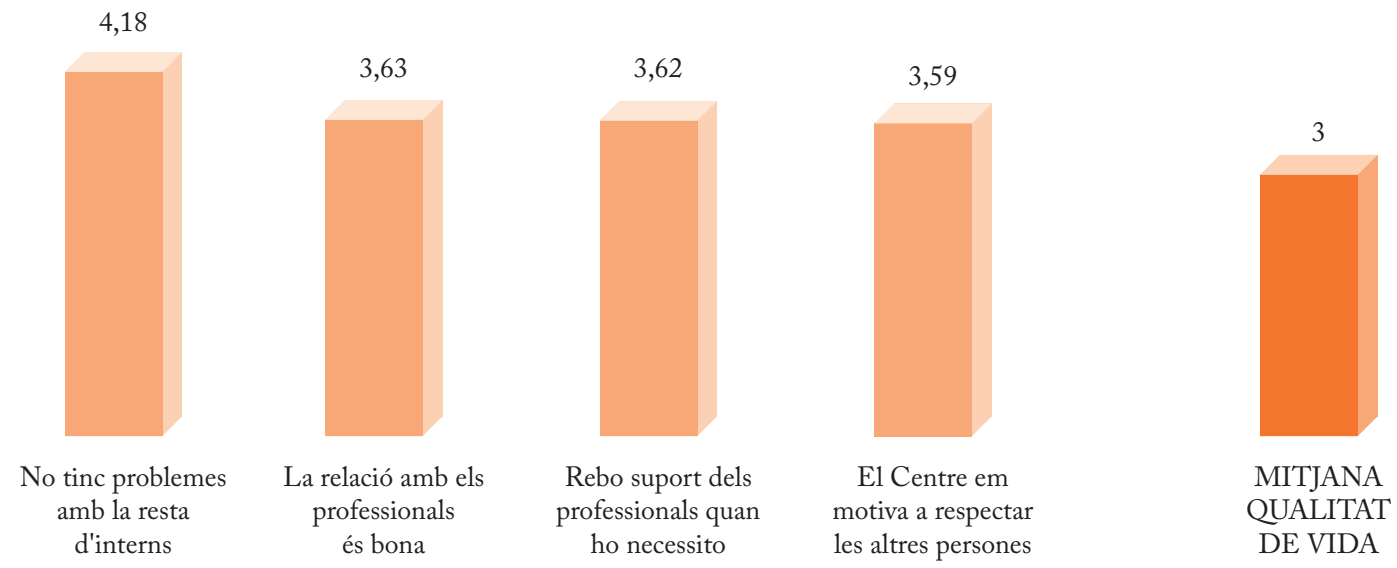

Queda palesa la importància del nou model en relació a la millora de la convivència, no només entre els interns, amb una valoració altament significativa en relació a la mitjana general, sinó també en relació amb els professionals. El foment d'espais de diàleg i participatius, així com la importància que es dona a les relacions informals en el pati o durant les activitats, són dos dels elements bàsics que evidencien un canvi en la cultura penitenciària. 
De nou, tant els professionals dels equips de tractament com els interns, coincideixen en identificar en les entrevistes realitzades, els beneficis d'aquest canvi cultural en la concepció del sistema penitenciari. Un espai d'aprenentatge mutu en el que s'identifiquen els diferents agents des d'un prisma d'horitzontalitat però amb rols i tasques diferenciades.

"Ells estan aprenent que tenen veu i nosaltres aprenem que tenen veu i entre tots ho hem de fer. Quan vas a una comissió has de deixar de mirar pel bé personal i passar a mirar pel bé general. Aprenem d'aquesta nova presó que volem tots" Cap de programes.

"Hi ha una massa de gent que acull uns quants poc a poc y els van encaminant. Hi ha qui fa el canvi i hi ha qui no, però molts cops de forma inconscient canvies. És important que tothom estigui unit per algo, és el que fa que que s'evitin mogudes, consums,... fa que s'assembli a un modulo de respecte" Intern

"És una altra part de donar aquesta nova identitat a l'intern, de passar de ser una persona passiva a ser una persona activa" Educadora social

La participació s'aprèn a través de la pràctica, i aquesta ha de possibilitar l'assumpció de valors de tipus prosocial que permetin consolidar el procés de incorporació social. Tant els interns com els propis equips de professionals, entenen la pràctica participativa com un espai d'aprenentatge i formació que, a través de la experiencialitat i vivencialitat de la pràctica acompanyada, millora el procés de transició a la comunitat i consolida el procés de reinserció, ja que permet un canvi en el procés d'identitat de la persona.

\subsection{Funcionament i organització dels sistemes de participació.}

Aquest model requereix d'espais de trobada i participació formal, entesos pels diferents agents les identifiquin com a espais de debat i treball conjunt. Aquests són, i han de ser, reconeguts per tots els equips de professionals i per l'estructura del centre, per tal que les propostes, canvis o demandes que se'n generin puguin tenir respostes adequades. Són espais horitzontals de treball en comú i on estan representats tots els agents que intervenen al mòdul o al centre. 


\section{Gràfic 4. Mitjana de respostes del qüestionari MQPL en relació a la gestió i participació dels espais deliberatius.}

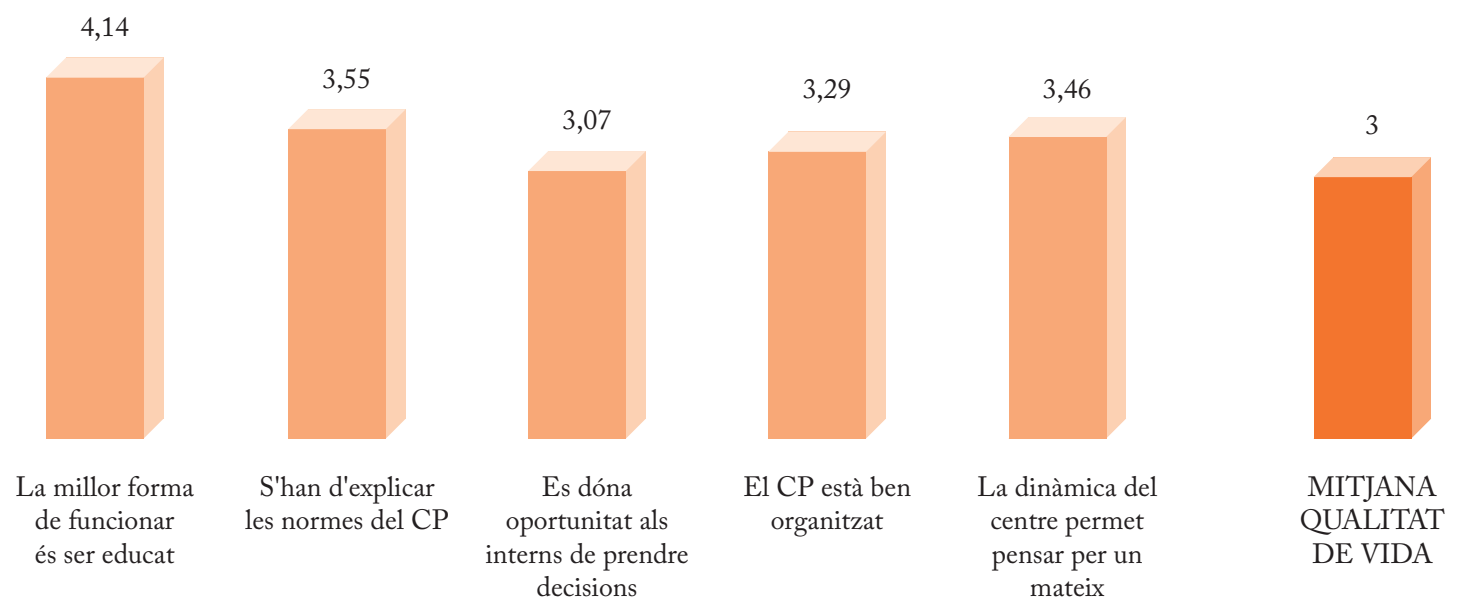

En el gràfic 4, i pel que es desprèn de les respostes aportades pels interns, s'evidencia la importància que tenen les normes de conducta i de relació en la participació i en la consecució dels objectius personals i grupals. Aquest augment evidencia un canvi significatiu en la cultura participativa que passa, de sistemes de rebel-lió per reclamar els propis drets, a l'ús d'espais participatius. En general es percep una bona valoració per part dels interns en relació a la possibilitat de tenir espais de participació, en la que la direcció i els professionals no condicionen la vida ni el procés participatiu dels propis interns. Un element cabdal per a que aquest espais siguin reals i efectius és l'apropament al sistema normatiu de la pròpia estructura penitenciària i el seu coneixement. Conèixer la norma ajudarà, de bona manera, a entendre els propis límits de la participació.

En aquesta línia, i especialment els equips de professionals del centre entrevistats, assenyalen les comissions i el Consell General de Centre com un espai participatiu i deliberatiu on mostrar opinions i fer suggeriments a la política penitenciaria del propi centre $\mathrm{i}$ a les accions que s'hi duen a terme. Els espais de participació son percebuts com a espais de treball i de canvi, espais de tractament i millora competencial dins del seu procés de canvi. La participació ha de ser acompanyada pels equips de professionals, permetent que els interns aprenguin noves formes de relació que permetran millorar el procés de incorporació social. 
"De fet hi ha hagut molts canvis d'organització del centre, més regimentals que tractamentals, i que han vingut a proposta dels interns. Es passa a la Comissió General de Centre $i$ allà és on hi ha tota la direcció que pot fer canvis" Educadora social

"A les diferents comissions que hi ha al mòdul, no només puc participar jo sinó que el Centre ofereix a tothom la possibilitat de participar en els canvis" Intern

"Quan hi ha hagut algun problema els interns s'acaben expressant. Abans no hi havia aquests espais i era com una olla a pressió, era quan hi havia els plantes i els motins" Cap d'Unitat

"Però aquest sistema de participació necessita que tant pel centre com pel propi interns s'acopli bé la maquinària" Funcionari d'interior

Segons el que es desprèn de les entrevistes, es pot evidenciar com el Centre Penitenciari incorpora els espais participatius com un espai propi de creixement i de construcció cultural, que ha de permetre millora la relació entre els agents, així com construir un entorn agradable i més adequat per facilitar la intervenció educativa. La finalitat, d'aquests espais és, i ha de ser, l'exercici experiencial de valors prosocials que han de permetre millorar les seves competències ciutadanes.

\section{Conclusions}

La creació d'espais de participació on els interns, professionals i colllaboradors dialoguin per la millora de la gestió i acció penitenciària, no repercuteix per si sola en la millora del procés de reinserció social, però si permet incidir en aspectes crítics que afavoreixen aquest procés. La pràctica participativa aporta aprenentatge i pràctica de valors prosocials que han de permetre la pràctica de competències pròpies de la ciutadania activa i participativa. Tanmateix, com es pot veure en aquest article, els models de base participativa és un dels elements bàsics i essencials per tal de poder afavorir climes adequats pel canvi. Un clima que permete superar antics models penitenciaris basats en la confrontació, i on es fomenta el vincle professionals-interns que ha de ser un element clau i afavoridor del procés de canvi. 
El desistiment és el procés en el que una persona decideix canviar el seu tipus de comportament en relació al fet delictiu. És evident que aquest és un canvi personal, però no podem obviar que els Centres Penitenciaris han de possibilitar i cercar aquests processos a través d'intervencions intencionals i organitzades. La participació, i especialment els espais de participació, són espais que fomenten el procés de desisitment en tant en quant:

- permeten un vincle amb agents de la comunitat, tant grups d'iguals com equips de professionals i col-laboradors,

- són espais transmissors de valors prosocials, la seva pràctica està imbuïda de valors socials positius que milloren la cohesió social i permeten la construcció de identitats comunitàries.

- Són espais experiencials i vivencials, on, a través de la pràctica s'evidencia la capacitat del subjecte a construir nous processos d'identitats personals i comunitàries, apoderant-lo en el procés de canvi.

Tot plegat, i d'acord a les teories dels vincles socials, es pot afirmar que la gestió organitzada de sistemes participatius, que arribin a tota la població interns i de la que en formin part els equips de professionals, ha de permetre el foment dels processos de desistiment. Un desistiment que suposa la millora de competències socials fent èmfasi no només en la reducció de factors de risc, sinó també en la millora de factors protectors a través de la construcció de noves identitats. Un desistiment que ha de dur a una reducció de la reincidència penitenciaria, junt a una millora del procés de reinserció social.

\section{Bibliografia}

Alonso I i Funes J (2009) L'acompanyament social en els recursos socioeducatius a Educación Social. Revista d'intervenció socioeducativa vol 42

Barbero JM i Cortés F (2005) Trabajo comunitario, organización y desarrollo social, Madri$\mathrm{d}$ :Alianza editorial 
Bustamante Y, Álvarez L i Herrera E (2016) Apoyo social percibido y su influencia en el desistimiento delictivo: Evaluación del rol institucional a Psicoperspectivas. Individuos y Sociedad vol 15(01)

Capdevila M (2014) Taxa de reincidència penitenciaria 2014, Barcelona:CEJFE

Caride, J. A., \& Gradaílle, R. (2013). Educar en las cárceles: nuevos desafíos para la educación social en las instituciones penitenciarias. Revista de Educación, 360, 36-47.

Cervelló, V (2005) El sentido actual del principio constitucional de reeducación y reinserción social a Presente y futuro de la Constitución Española de 1978, Valencia:Tirant lo Blanch

Del Pozo FJ i Añaños F (2013) La educación social penitenciaria $\dot{¿}$ De donde venimos y hacia donde vamos? a Revista Complutense de Educación vol 24(01)

Diaz S, Mendoza V, Porras C (2011) Una guia para la elaboración de estudios de caso a Razon y Palabra num 75

Enjuanes J, Escribano X i Sanchez J (2016) La Pedagogía Social Comunitaria como modelo de intervención socioeducativa en Centros Penitenciarios a Morata T (coord) Pedagogía Social Comunitaria y Exclusión Social, Madrid:Editorial Popular

Enjuanes J, Garcia F i Longoria B (2014) La Unidad Terapéutica y Educativa del Centro Penitenciario de Villabona, un nuevo modelo penal de reinserción social a Revista Educació Social. Revista d'intervenció socioeducativa vol 57

Enjuanes, J., \& Vinyals, O. (2016). Voluntariado y educación social en prisiones. Una experiencia de participación integral en el proceso de cambio de las personas privadas de libertad - RES. Revista de Educación Social. RES - Revista de Educación Social, 22.

Fernandez C (2013) Sobre los peligros del punitivismo a InDret vol 3

Garland D (2005) La cultura del control Madrid: Editorial Gedisa 
Calan D (2015) Los módulos de respeto: una alternativa al tratamiento penitenciario, Madrid:Universidad Complutense de Madrid

Generalitat de Catalunya. (s.d.) "Model de Participació i Convivència” Recuperat el 15 agost 2018, de Departament de Justícia, Lloc web: http://justicia.gencat.cat/ca/ambits/reinsercio_i_serveis_penitenciaris/participacio-i-convivencia-centres/

------ (s.d.-b) “Taula de Participació Social” Recuperat el 15 d'agost de 2018, Departament de Justicia. Lloc Web: http://justicia.gencat.cat/ca/ambits/reinsercio_i_serveis penitenciaris/collaboracio institucional/funcions i principis/

Generalitat de Catalunya. (2011). El model de rehabilitació a les presons catalanes. (G. de Catalunya, Ed.). Barcelona.

Gil F (2010) La acción pedagògica en las prisiones. Posibilidades y limites a Revista Española de Pedagogía vol 245 pp49-64

----- (2013) Derechos humanos y reeducación en las prisiones. El derecho a la educación en el modelo good lives a Revista de Educación vol 360 pp48-68

Hirschi, T. (2003). Una teoria del control de la delincuencia. Capitulo criminológico, 31(4), 5-31.

Jackobs, G (2003) Derecho penal del enemiga Madrid:Civitas Ediciones

Laub J i Sampson R (2001) understanding desistance for crime a Crime and Justice vol 28, pp 1.69

Liebling A, Hulley S i Crewe B (2011) Conceptualsing and measuring the quality of prison life a Hanbook of criminological research methods, London: SAGE

Lorenzo C (2013) Cárceles en llamas Barcelona:Virus editorial 
Marcuello-Servós, C., \& García-Martínez, J. (2011). La cárcel como espacio de de-socialización ciudadana: ¿fracaso del sistema penitenciario español? Portularia. Revista de Trabajo Social, 11(1), 49-60.

Marti J i Cid J (2015) Encarcelamiento, lazos familiares y reincidència. Explorando los límites del familismo a Revista Internacional de Sociologia vol 73(01)

Maruna S (2001) Making Good. How ex-convicts reform and rebuild their lives, Washington: American Psycological Association

McNeill F (2016) El paradigma del desistimiento en la gestión de delincuentes a InDret vol1

Morata T (2014) Pedagogía Social Comunitaria: un modelo de intervención socioeducativa integral a Revista Educación Social: revista de intervención socioeducativa num 57

Prat, T., \& Cullen, F. (2000). The empirical status of Gottfredson and Hirschi's general theory of crime: a meta-analysis. criminology, 38(3), 931-964.

Rodriguez F, Garcia F i Álvarez E (2013) Educar en las cárceles: Unidad Terapéutica y Educativa de Villabona (Asturias, España) a Revista Criminalidad vol 55(02)

Rodriguez J, Larrauri E i Güerri C (2018) Percepción de la calidad de vida en prisión. La importància de una buena organización y un trato digno a Revista Internacional de Sociología vol 76(02)

Tamarit JM (2016) El sistema penitenciari català. Fonament $i$ exercici de la competència a Revista d'iEstudis Autonòmics i Federals vol 23 pp 235-273

Trilla J (2010) La educación ciutadana y la escuela. Propuestas conceptuales para clarificar el debate sobre la educación para la ciutadania en la escuela a Valdivieso S i Almeida A (eds) Educación y ciutadania, Las Palmas:Anroart Editorial

Trilla, J i Novella AM (2011) Participación, democràcia y formación para la ciutadania. Los consejos de infancia a Revista de Educaciónvol 356 pp 23-43 
Valverde, J. (2014). Exclusión social. Bases teóricas para a intervención. (Editorial Popular, Ed.). Madrid.

Yin, R (1984) Investigación sobre estudio de caso. Diseño y métodos. Londres:Editorial SAGE

Zubero I (2006) El derecho a la participación a Foro Internacional de Experiencias de Participación "OKUPando Ciudadanía” Sevilla:Universidad de Sevilla

- (2014) Participación, ciudadanía y exclusión social a Revista d'Educación Social. Revista d'Intervenció socioeducativa vol 57 
Xedagogia i Treball Social

Revista de Ciències Socials Aplicades

Edita: Universitat de Girona

Disseny i maquetació: info@clam.cat · 647427732

Dipòsit Legal: GI.904-2010

ISSN: 2013-9063 